\title{
Implementing Asthma Guidelines Using Practice Facilita- tion and Local Learning Collaboratives: A Randomized Controlled Trial
}

James W. Mold, MD, MPH

Chester Fox, $M D^{4}$

Angela Wisniewski, PbarmD ${ }^{4}$

Paula Darby Lipman, $P b D^{2}$

Margot R. Krauss, $M D, M P H^{2}$

D. Robert Harris, $P b D^{2}$

Cheryl Aspy, PbD ${ }^{1}$

Rachel A. Coben, $\mathrm{MPH}^{2}$

Kurt Elward, $M D^{3}$

Paul Frame, $M D^{5}$

Barbara P. Yawn, $M D^{6}$

Leif I. Solberg, $M D^{7}$

René Gonin, PhD

'University of Oklahoma Health Sciences Center, Oklahoma City, Oklahoma

${ }^{2}$ Westat, Rockville, Maryland

${ }^{3}$ University of Virginia, Charlottesville, Virginia

${ }^{4}$ New York State University, Buffalo, New York

${ }^{5} 3131$ Avon Rd, Geneseo, New York

${ }^{6}$ Olmsted Medical Center, Rochester, Minnesota

${ }^{7}$ Health Partners, Minneapolis, Minnesota

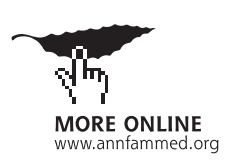

Conflict of Interest: authors report none.

\section{CORRESPONDING AUTHOR}

James W. Mold, MD, MPH

University of Oklahoma Health Sciences

Center

900 NE 10th St

Oklahoma City, OK 73104

james-mold@ouhsc.edu

\begin{abstract}
PURPOSE Guideline implementation in primary care has proven difficult. Although external assistance through performance feedback, academic detailing, practice facilitation (PF), and learning collaboratives seems to help, the best combination of interventions has not been determined.

METHODS In a cluster randomized trial, we compared the independent and combined effectiveness of PF and local learning collaboratives (LLCS), combined with performance feedback and academic detailing, with performance feedback and academic detailing alone on implementation of the National Heart, Lung and Blood Institute's Asthma Guidelines. The study was conducted in 3 primary care practice-based research networks. Medical records of patients with asthma seen during pre- and postintervention periods were abstracted to determine adherence to 6 guideline recommendations. McNemar's test and multivariate modeling were used to evaluate the impact of the interventions.
\end{abstract}

RESULTS Across 43 practices, 1,016 patients met inclusion criteria. Overall, adherence to all 6 recommendations increased $(P \leq .002)$. Examination of improvement by study arm in unadjusted analyses showed that practices in the control arm significantly improved adherence to 2 of 6 recommendations, whereas practices in the PF arm improved in 3, practices in the LLCs improved in 4, and practices in the PF + LLC arm improved in 5 of 6 recommendations. In multivariate modeling, PF practices significantly improved assessment of asthma severity (odds ratio $[\mathrm{OR}]=2.5,95 \% \mathrm{Cl}, 1.7-3.8)$ and assessment of asthma level of control $(\mathrm{OR}=2.3$, $95 \% \mathrm{Cl}, 1.5-3.5)$ compared with control practices. Practices assigned to LLCs did not improve significantly more than control practices for any recommendation.

CONCLUSIONS Addition of PF to performance feedback and academic detailing was helpful to practices attempting to improve adherence to asthma guidelines.

Ann Fam Med 2014;233-240. doi: 10.1370/afm.1624.

\section{INTRODUCTION}

Tmplementation of clinical practice guidelines for managing chronic diseases can be challenging for primary care practices. Despite the availability since 1991 of the guidelines sponsored by the National Heart, Lung and Blood Institute (NHLBI) and produced by the National Asthma Education and Prevention Program (NAEPP), fewer than $40 \%$ of asthma care notes include information about symptoms, missed activities, and environmental triggers. ${ }^{1-4}$ A 2001 survey of more than 60,000 patients treated by 4,901 primary care physicians found that while $62 \%$ of pediatric patients and $68 \%$ of adult patients reported more than 2 symptomatic days in the past week, only $60 \%$ had a prescription for a controller medication. ${ }^{5}$ Other studies found that practices prescribing a corticosteroid inhaler ranged from $15 \%$ among patients with moderate to severe asthma to $72 \%$ among patients with severe asthma. ${ }^{6,7}$ Between $0 \%$ and $50 \%$ of parents of asthmatic children report having received an action plan. ${ }^{7-10}$

Simple dissemination strategies, combined with clinician education, 
toolkits, and performance feedback, have little impact on guideline implementation. ${ }^{11-15}$ More intensive forms of assistance and multicomponent interventions may be more helpful. ${ }^{16-19}$ Two promising types of assistance are practice facilitation $(\mathrm{PF})^{20-22}$ and learning collaboratives. ${ }^{23-27}$ Assumptions behind PF are that many practices are inadequately resourced, lack the experience and skills required, and are so unique that each must implement innovations differently. Relationships between practice facilitators and practice staff appear to be critical to success, resembling the Cooperative Extension, where agents develop relationships with families to facilitate implementation of evidence-based farming practices. ${ }^{28}$

Peer-to-peer learning has been found to motivate changes in practice. ${ }^{29}$ Learning collaboratives create opportunities for improvement within a framework of competition and urgency. Learning collaboratives typically involve large numbers of practices that receive education, perform medical record reviews, develop registries, and work collaboratively to implement evidence-based strategies. Although studies evaluating the effectiveness of collaboratives have produced mixed results, collaboratives remain a widely used approach. ${ }^{30}$ Our experience suggests that the same motivation, competition, and collaborative learning generated in large collaboratives can be achieved by small numbers of practices meeting more often and for shorter periods of time, and that these local learning collaboratives (LLCs) are well-accepted by clinicians and staff. ${ }^{31}$

There is no literature directly comparing the effectiveness of PF and LLCs. We therefore conducted a cluster randomized trial comparing the 2 interventions, separately and together, with performance feedback and academic detailing alone on implementation of asthma guideline recommendations.

\section{METHODS}

\section{Study Design}

The study was a 6-month, cluster randomized controlled trial, in which we randomly assigned practices in close geographic proximity (to facilitate LLC implementation) in clusters of 3 to 1 of 4 study arms: (1) PF alone, (2) LLC alone, (3) PF + LLC, and (4) control. We focused on 6 key guideline recommendations from the NAEPP, ${ }^{32}$ based upon input from our asthma experts (K.E., B.Y.): (1) documentation of intermittent vs persistent asthma (severity assessment), (2) assessment of exposure to environmental triggers, (3) assessment of level of control, (4) prescription of controller medications for persistent asthma, (5) a written asthma action plan, and (6) planned asthma visits. Participating primary care practices were members of 3 practice-based research networks, 1 in Oklahoma and 2 in western New York.

\section{Interventions}

All practices received performance feedback, academic detailing, summaries of NHLBI asthma guidelines, and a toolkit, which included the Asthma Control Test, the Asthma APGAR, ${ }^{33}$ and action plan templates in English and Spanish. A clinician to help each practice develop an improvement plan provided academic detailing, including performance feedback based on record abstractions and information on best indigenous practices.

In addition, practices assigned to PF and PF + LLC received assistance from a practice facilitator who visited practices for a half-day weekly or a full day every other week for 6 months to assist the practice in meeting their target goals.

Practices assigned to LLC and PF + LLC were expected to meet once a month for at least 1 hour for 6 months to review each other's performance data, discuss successful and unsuccessful strategies, and refine plans for implementing guideline recommendations.

\section{Data Collection}

We used PF field notes and LLC minutes to assess fidelity to intervention expectations. Eighteen months after the start of the intervention, patient records were abstracted by trained medical record abstractors using standardized forms to collect information pertinent to the 6 guideline recommendations. For each practice, the goal was to abstract information from 60 records of patients meeting the following criteria: an International Classification of Disease, Ninth Revision (ICD-9) code for asthma (493.xxx), born between 1956 and 2004, and at least 1 visit for asthma between 9 months before and 18 months after the academic detailing session. Reasons for visits were classified as primary asthma-related visit (including routine followup for asthma and symptomatic asthma), other asthmarelated visit (visit for another concern where asthma was addressed), and non-asthma-related visit (vaccinations, other acute or chronic disease visits where asthma was not addressed). We neither abstracted nor counted nonasthma-related visits during the process.

\section{Key Outcomes}

Evidence of guideline implementation was determined during 2 periods: 9 -months preintervention and 18 -months postintervention ( 6 months of active intervention and 12-months afterward). Information from all asthma-related visits during each period was used in determining evidence for implementation of each guideline recommendation.

We considered asthma severity to be assessed if the type of asthma was ever described as intermittent, mild, moderate, or severe persistent, exerciseinduced bronchospasm, or asthmatic bronchitis, or if spirometry showed a forced expiratory volume in the 
first second of expiration $\left(\mathrm{FEV}_{1}\right)$ of less than $80 \%$. We considered any mention of asthma triggers or evidence that patients were asked about exposure to secondhand smoke as assessment of environmental triggers. An asthma action plan had to be evident in the medical record. The denominator for asthma severity, assessment of environmental triggers, and asthma action plan was all active patients with at least 1 asthma-related visit in both time periods.

Assessment of asthma level of control was defined as documentation of at least 3 of the following: daytime symptoms, nighttime symptoms, symptoms while exercising (or playing), missing school or work, use of rescue inhaler, and office measurement of peak expiratory flow rate. The denominator was the total number of asthma-related visits in each period.

We looked for evidence of a prescription for asthma controller medication (inhaled corticosteroid, inhaled corticosteroid plus a long-acting beta agonist, or leukotriene inhibitor) among persistent asthmatic patients, defined as all asthmatic patients referred to as having persistent asthma or given a controller medication. The denominator was all patients with persistent asthma seen at least once during both periods. We examined the number of patients whose clinician recommended a follow-up visit in the next 12 months relative to all those patients with at least 1 primary asthma-related visit in both time periods.

There were 4 baseline practice characteristics considered to be potential modifying variables: use of electronic health record (EHR), presence of midlevel clinician (physician assistant or nurse practitioner), clinician ownership (yes/no), and number of clinicians in the practice.

\section{Statistical Analyses}

Practice characteristics were described in terms of frequencies and proportions, with possible differences between study arms assessed using the Fisher exact test. We used the McNemar test for unadjusted comparisons of the proportions of patients receiving each recommended guideline among patients seen in both the pre- and postintervention period. We used generalized estimating equation (GEE) models to assess whether the covariate-adjusted pre- to postintervention change differed between the 3 intervention arms and the control arm for each guideline implementation measure. Modeling included study arm, study period (post- vs preintervention), the interaction of study arm with study period, and 5 covariates: presence of mid-level clinicians, clinician-owned practice, practice size, medical record type, and the practicebased research network location. The GEE approach was used to fit repeated measures models (SAS Institute, Inc), using a step-down likelihood approach to eliminate covariates that did not contribute significantly to the model. A significant interaction of study arm with study period would indicate that change over time in an outcome differed significantly among study arms.

Because the planned implementation strategies may not have been applied equally across practices, we defined adequate adherence for LLC and PF sites as follows: minimum of 3 (of 6) LLC meetings, a minimum of 12 (of a possible 24) PF visits. Sites assigned to receive both interventions had to meet minimum standards for each. To further investigate the effect of the interventions, we refit the final models developed on all practices to the data excluding those that did not adequately adhere to the assigned interventions.

The Institutional Review Boards at the University of Oklahoma Health Sciences Center and the State University of New York in Buffalo approved the study.

\section{RESULTS}

Practice Characteristics and Study Population Of the 51 practices recruited, 45 enrolled in the study. Two practices could not participate in final medical record abstraction, leaving 43 with baseline characteristics that did not differ significantly between study arms (Table 1). Of the 2,226 patients meeting abstrac-
Table 1. Practice Characteristics by Study Arm

\begin{tabular}{|c|c|c|c|c|c|}
\hline Practice Characteristic & LLC & PF & PF + LLC & Control & $P$ Value $^{a}$ \\
\hline Participating practices, No. & 10 & 10 & 12 & 11 & NA \\
\hline \multicolumn{6}{|l|}{ Medical record type, No. (\%) } \\
\hline Electronic health record & $4(40)$ & $8(80)$ & $9(75)$ & $5(45)$ & \multirow[t]{2}{*}{.14} \\
\hline Paper & $6(60)$ & $2(20)$ & $3(25)$ & $6(55)$ & \\
\hline \multicolumn{6}{|l|}{ Mid-level practitioners, No. (\%) } \\
\hline Yes & $6(60)$ & $6(60)$ & $9(75)$ & $6(55)$ & \multirow[t]{2}{*}{.76} \\
\hline No & $4(40)$ & $4(40)$ & $3(25)$ & $5(45)$ & \\
\hline \multicolumn{6}{|l|}{ Practice size, No. (\%) } \\
\hline 1 & $3(30)$ & $2(20)$ & $2(17)$ & $2(18)$ & \multirow[t]{4}{*}{.67} \\
\hline 2 & $2(20)$ & $2(20)$ & $3(25)$ & $2(18)$ & \\
\hline $3-5$ & $4(40)$ & $1(10)$ & $3(25)$ & $5(45)$ & \\
\hline$\geq 6$ & $1(10)$ & $5(50)$ & $4(33)$ & $2(18)$ & \\
\hline \multicolumn{6}{|l|}{ Clinician owned, No. (\%) } \\
\hline Yes & $6(60)$ & $5(50)$ & $5(42)$ & $4(36)$ & \multirow[t]{2}{*}{.72} \\
\hline No & $4(40)$ & $5(50)$ & 7 (58) & 7 (64) & \\
\hline
\end{tabular}


Table 2. Unadjusted Analyses of Guideline Implementation for the Overall Study Population

\begin{tabular}{|c|c|c|c|c|c|c|}
\hline $\begin{array}{l}\text { Study Population } \\
\text { of Interest }\end{array}$ & Outcome Measure & $\begin{array}{l}\text { Matched } \\
\text { Pairs } \\
\text { No. }\end{array}$ & $\begin{array}{c}\text { Preintervention } \\
\%\end{array}$ & $\begin{array}{c}\text { Postintervention } \\
\%\end{array}$ & $\underset{\%}{\text { Change }}$ & $P$ Value \\
\hline \multirow[t]{3}{*}{ All asthmatic patients } & Assessment of asthma severity & 977 & 37 & 56 & 19 & $<.001$ \\
\hline & $\begin{array}{l}\text { Assessment of environmental } \\
\text { triggers }\end{array}$ & 1,016 & 38 & 52 & 14 & $<.001$ \\
\hline & Asthma action plan & 983 & 7 & 11 & 4 & .002 \\
\hline At each asthma visit & Assessment of level of control & 937 & 40 & 56 & 16 & $<.001$ \\
\hline $\begin{array}{l}\text { All patients with per- } \\
\text { sistent asthma }\end{array}$ & Asthma controller medications & 867 & 82 & 87 & 5 & .002 \\
\hline Primary asthma visit & Asthma follow-up visits & 410 & 72 & 79 & 7 & .002 \\
\hline
\end{tabular}

Table 3. Unadjusted Analyses of Guideline Implementation by Study Arm of Matched Pairs

\begin{tabular}{|c|c|c|c|c|c|c|c|c|c|c|c|c|c|}
\hline \multirow[b]{2}{*}{$\begin{array}{l}\text { Study Population } \\
\text { of Interest }\end{array}$} & \multirow[b]{2}{*}{ Outcome Measure } & \multicolumn{3}{|c|}{ Control } & \multicolumn{3}{|c|}{ PF } & \multicolumn{3}{|c|}{ LLC } & \multicolumn{3}{|c|}{ PF + LLC } \\
\hline & & No. & $\begin{array}{c}\text { Pre } \\
\%\end{array}$ & $\begin{array}{c}\text { Post } \\
\%\end{array}$ & No. & $\begin{array}{c}\text { Pre } \\
\%\end{array}$ & $\begin{array}{c}\text { Post } \\
\%\end{array}$ & No. & $\begin{array}{c}\text { Pre } \\
\%\end{array}$ & $\begin{array}{c}\text { Post } \\
\%\end{array}$ & No. & $\begin{array}{c}\text { Pre } \\
\%\end{array}$ & $\begin{array}{c}\text { Post } \\
\%\end{array}$ \\
\hline \multirow[t]{3}{*}{ All asthmatic patients } & $\begin{array}{l}\text { Assessment of asthma } \\
\text { severity }\end{array}$ & 188 & 45 & $56^{a}$ & 283 & 42 & $71^{\mathrm{a}}$ & 196 & 28 & $39^{a}$ & 310 & 33 & $52^{a}$ \\
\hline & $\begin{array}{l}\text { Assessment of envi- } \\
\text { ronmental triggers }\end{array}$ & 192 & 58 & $70^{a}$ & 290 & 42 & $57^{a}$ & 202 & 17 & 24 & 332 & 36 & $54^{a}$ \\
\hline & Asthma action plan & 180 & 13 & 15 & 282 & 7 & 10 & 199 & 3 & $8^{b}$ & 322 & 7 & 11 \\
\hline At each asthma visit & $\begin{array}{l}\text { Assessment of level of } \\
\text { control }\end{array}$ & 172 & 44 & 45 & 276 & 55 & $73^{a}$ & 276 & 24 & $45^{a}$ & 301 & 34 & $54^{a}$ \\
\hline $\begin{array}{l}\text { All patients with } \\
\text { persistent asthma }\end{array}$ & $\begin{array}{l}\text { Asthma controller } \\
\text { medications }\end{array}$ & 153 & 79 & 80 & 254 & 84 & 87 & 188 & 78 & $87^{b}$ & 289 & 84 & $91^{\mathrm{b}}$ \\
\hline Primary asthma visit & Asthma follow-up visits & 66 & 62 & 70 & 111 & 78 & 83 & 78 & 65 & 72 & 155 & 74 & $84^{b}$ \\
\hline
\end{tabular}

tion criteria, 211 had no asthma-related visits during the 27-month study period, and 12 did not include all required information, leaving 2,003 patients with 7,106 visits for whom asthma was addressed. Among these patients, 1,016 had at least 1 asthma-related visit in both the pre- and postintervention periods. Implementation of guideline recommendations was based on these 1,016 patients. The patients were demographically similar between study arms; overall $56 \%$ were female, $67 \%$ reported allergies, and $96 \%$ had no concurrent diagnosis of chronic obstructive pulmonary disease $(P>.5)$ (data not shown).

\section{Matched Pairs Analyses}

Implementation of all 6 guideline recommendations increased significantly postintervention in the overall study population in the unadjusted analyses $(P \leq .002)$ (Table 2). Matched pairs analyses within each study arm are displayed in Table 3. Significant improvements were seen for 2 guideline recommendations in the control group, 3 in the PF arm, 4 in the LLC arm, and 5 in the PF + LLC arm. For descriptive purposes, a table showing the percentage change in implementation of each of the guideline recommendations by practice within intervention arm is available as a Supplemental Appendix. There was an apparent deterioration of performance of 1 guideline recommendation in 3 of the practices and deterioration of performance of 2 recommendations in 1 practice. Given the small number of asthmatic patients seen in these practices, these changes may or may not be indicative of a potential adverse effect of the interventions.

\section{Multivariate GEE Modeling}

The interaction of study arm with study period contributed significantly to the assessment of severity model $(P=.002)$ (Table 4$)$. The pre- to postintervention improvement in assessment of severity was 2.5 times (95\% CI, 1.7-3.8) higher in the PF practices compared with control practices. With respect to additional covariates, the odds of having an asthma severity assessment were approximately $40 \%$ lower for those practices with EHRs and $80 \%$ higher for practices with mid-level practitioners (odds ratio $[\mathrm{OR}]=0.6,95 \% \mathrm{CI}$, $0.5-0.8$, and $\mathrm{OR}=1.8,95 \% \mathrm{CI}, 1.3-2.4$, respectively). 
Interaction of study arm with study period also contributed significantly to assessment of level of control $(P=.005)$, with assessment of level of control significantly higher for the PF practices compared with control practices $(\mathrm{OR}=2.3,95 \% \mathrm{CI}, 1.5-3.5)$. Clinician-owned practices and those with only 2 clinicians had higher odds of improving assessment of asthma level of control $(\mathrm{OR}=1.5,95 \% \mathrm{CI}, 1.2-1.9$, and $\mathrm{OR}=1.5,95 \% \mathrm{CI}, 1.2-2.0$, respectively).

Improvement in assessment of environmental triggers did not differ by study arm $(P=.58)$. Practices with EHRs, practices with 2 to 5 clinicians, and clinician-owned practices, however, were more likely to improve in assessment of environmental triggers $(\mathrm{OR}=1.6,95 \% \mathrm{CI}, 1.2-2.2$ for practices with EHRs; $\mathrm{OR}=1.9,95 \% \mathrm{CI}, 1.4-2.6$ for 2 -clinician practices; $\mathrm{OR}=1.6,95 \% \mathrm{CI}, 1.1-2.4$ for 3 - to 5 -clinician prac- tices; and $\mathrm{OR}=1.6,95 \% \mathrm{CI}, 1.3-2.1$, for clinicianowned practices).

Although change in presence of a written asthma action plan did not differ by study arm $(P=.24)$, several covariates were associated with this outcome as well. Practices with EHRs and those with a mid-level practitioner or 1 clinician were less likely to increase their use of asthma action plans $(\mathrm{OR}=0.6,95 \% \mathrm{CI}$, $0.4-0.9 ; \mathrm{OR}=0.5,95 \% \mathrm{CI}, 0.3-0.9 ;$ and $\mathrm{OR}=0.3,95 \%$ CI, 0.1-0.8, respectively).

Prescription of an asthma controller medication, already high at baseline, and recommendation for an asthma follow-up visit also did not differ by study arm $(P>.2)$. Change in controller medication prescription was not affected by practice characteristics. Practice size of 2 clinicians significantly increased asthma follow-up visit recommendations $(\mathrm{OR}=3.0,95 \% \mathrm{CI}$,

Table 4. Multivariable Modeling of the Pre- to Postintervention Change in the Outcome Measures by Study Arm

\begin{tabular}{|c|c|c|c|c|c|c|}
\hline Variable & $\begin{array}{l}\text { Assessment of } \\
\text { Asthma Severity } \\
\text { OR }(95 \% \mathrm{Cl})\end{array}$ & $\begin{array}{c}\text { Assessment of } \\
\text { Environmental } \\
\text { Triggers } \\
\text { OR }(95 \% \mathrm{Cl})\end{array}$ & $\begin{array}{c}\text { Asthma } \\
\text { Action Plan } \\
\text { OR }(95 \% \mathrm{Cl})\end{array}$ & $\begin{array}{l}\text { Assessment of } \\
\text { Level of Control } \\
\text { OR }(95 \% \mathrm{Cl})\end{array}$ & $\begin{array}{l}\text { Asthma } \\
\text { Controller } \\
\text { Medications } \\
\text { OR }(95 \% \mathrm{Cl})\end{array}$ & $\begin{array}{c}\text { Asthma } \\
\text { Follow-up } \\
\text { Visits } \\
\text { OR }(95 \% \mathrm{CI})\end{array}$ \\
\hline \multicolumn{7}{|c|}{$\begin{array}{l}\text { Interaction of study } \\
\text { arm with study } \\
\text { period }\end{array}$} \\
\hline LLC & $0.5(0.3-0.7)$ & $\ldots$ & $\ldots$ & $0.8(0.5-1.2)$ & $\ldots$ & $\ldots$ \\
\hline PF & $2.5(1.7-3.8)$ & $\ldots$ & $\ldots$ & $2.3(1.5-3.5)$ & $\ldots$ & $\ldots$ \\
\hline $\mathrm{PF}+\mathrm{LLC}$ & $1.0(0.7-1.5)$ & $\ldots$ & $\ldots$ & $1.1(0.7-1.7)$ & $\ldots$ & $\ldots$ \\
\hline Control & 1.0 & $\ldots$ & $\ldots$ & 1.0 & $\ldots$ & $\ldots$ \\
\hline$P$ value & .002 & .58 & .24 & .005 & .24 & .83 \\
\hline \multicolumn{7}{|c|}{ Medical record type } \\
\hline Electronic & $0.6(0.5,-0.8)$ & $1.6(1.1-2.2)$ & $0.6(0.4-0.9)$ & & & \\
\hline Paper & 1.0 & 1.0 & 1.0 & & & \\
\hline$P$ value & $<.001$ & .005 & .020 & $\ldots$ & $\ldots$ & $\ldots$ \\
\hline \multicolumn{7}{|c|}{$\begin{array}{l}\text { Mid-level } \\
\text { practitioners }\end{array}$} \\
\hline Yes & $1.8(1.3-2.4)$ & $\ldots$ & $0.5(0.3,0.9)$ & $\ldots$ & $\ldots$ & $\ldots$ \\
\hline No & 1.0 & $\ldots$ & 1.0 & $\ldots$ & $\ldots$ & \\
\hline$P$ value & $<.001$ & $\ldots$ & .011 & $\ldots$ & $\ldots$ & $\ldots$ \\
\hline \multicolumn{7}{|l|}{ Practice size } \\
\hline 1 & $\ldots$ & $0.7(0.4-1.1)$ & $0.3(0.1-0.8)$ & $1.0(0.7-1.5)$ & $\ldots$ & $1.5(0.7-3.2)$ \\
\hline 2 & $\ldots$ & $1.9(1.4-2.6)$ & $1.5(0.9-2.4)$ & $1.5(1.2-2.0)$ & $\ldots$ & $3.0(1.6-5.5)$ \\
\hline $3-5$ & $\ldots$ & $1.6(1.1-2.4)$ & $0.9(0.5-1.7)$ & $0.8(0.6-1.1)$ & $\ldots$ & $1.2(0.7-2.1)$ \\
\hline$\geq 6$ & $\ldots$ & 1.0 & 1.0 & 1.0 & $\ldots$ & 1.0 \\
\hline$P$ value & $\ldots$ & $<.001$ & $<.001$ & $<.001$ & $\ldots$ & .001 \\
\hline \multicolumn{7}{|c|}{ Clinician owned } \\
\hline Yes & $\ldots$ & $1.6(1.3-2.1)$ & $\ldots$ & $1.5(1.2-1.9)$ & $\ldots$ & $0.3(0.2-0.5)$ \\
\hline No & $\ldots$ & 1.0 & $\ldots$ & 1.0 & $\ldots$ & 1.0 \\
\hline$P$ value & $\ldots$ & $<.001$ & $\ldots$ & $<.001$ & $\ldots$ & $<.001$ \\
\hline \multicolumn{7}{|l|}{ Region } \\
\hline New York & $0.6(0.5-0.8)$ & $1.3(1.0-1.6)$ & $0.2(0.2-0.4)$ & $1.5(1.2-1.9)$ & $0.7(0.5-0.9)$ & $1.9(1.3-3.0)$ \\
\hline Oklahoma & 1.0 & 1.0 & 1.0 & 1.0 & 1.0 & 1.0 \\
\hline$P$ value & $<.001$ & .038 & $<.001$ & $<.001$ & .006 & .004 \\
\hline
\end{tabular}


1.6-5.5), and clinician ownership decreased the odds of a follow-up recommendation $(\mathrm{OR}=0.3,95 \% \mathrm{CI}$, 0.2-0.5)

Significant differences by region were found for all outcome measures. Implementation of 3 guideline recommendations improved significantly in New York, whereas the other 3 showed significant improvement in Oklahoma. There was some variation in how the implementation strategies were implemented. For instance, practice facilitators in New York spent almost 3 times longer in each practice (3.8 hours per week compared with 1.3 hours in Oklahoma). Overall, practices in the PF + LLC study arm had fewer PF visits, on average, compared with those only receiving PF (11 vs 20), and New York practices found it more difficult to convene the full set of expected LLC sessions compared with Oklahoma practices.

To further explore implementation differences, the final models were fit to the data excluding 11 practices that did not adequately adhere to the interventions (4 LLC practices, 1 PF practice, and 6 practices assigned to PF + LLC were excluded because of inadequate exposure to $\mathrm{PF}$ ). The models fit to the data for sites adhering to the interventions did not differ appreciably from those models fit to the full data.

The mean number of postintervention asthmarelated visits differed among study arms $(P<.0001)$. In pairwise comparisons, the mean number of postintervention visits among those in the PF arm was greater (3.8) than that of participants included in the other study arms, which ranged from 2.7 for LLC arm to 3.0 for PF + LLC arm ( $P<.05$ using Bonferoni $t$ tests). No differences were detected in the mean number of postintervention asthma-related visits between these other study arms $(P>.05)$.

\section{DISCUSSION}

Participation in this quality improvement project led clinicians to better address the needs of patients with asthma. In unadjusted analyses, the intensity of the intervention appeared to correlate with effectiveness, with the control arm improving significantly on only 2 guideline recommendations, practices receiving PF improving on 3, those participating in LLC meetings improving on 4, and practices in the PF + LLC arm showing significant improvement on 5 of the 6 recommendations.

The unique aspect of this cluster randomized controlled trial was the ability to compare each intervention with the control arm, which provided additional evidence of the effectiveness of PF in motivating and supporting practice change. After controlling for covariates and comparing each intervention with a control arm, only PF proved more effective than control for 2 guideline recommendations-assessments of asthma severity and level of control. For these outcomes, PF was more effective even than PF + LLC, which was statistically no better than the control condition. This finding might be explained, in part, by less PF presence per week in PF + LLC practices, compared with PF-only practices. Although the extra visits among PF practices may have increased the probability of fulfilling the asthma guidelines for assessment of asthma severity, it does not rule out that primary care clinicians were addressing asthma more often in this study arm as a result of the efforts of the practice facilitators. The assessment of asthma level of control was not affected by the extra visits among PF practices, because this guideline was examined using all available visits.

We also examined practice-level contextual variables. Use of an EHR was associated with less improvement in assessment of asthma severity and use of asthma action plans, whereas practices with an EHR were more successful at improving assessment of environmental triggers. This finding suggests that practices are able to use EHRs to improve simple processes but have more trouble programming them to do more complex tasks like creating action plans, which argues for the need for more information technology support than provided in this project.

Presence of mid-level clinicians was expected to improve implementation of all guideline recommendations, but it was associated only with improvement in assessment of asthma severity, whereas practices with mid-level clinicians were less likely to increase their use of action plans. Region of practice was statistically associated with implementation of all 6 guideline recommendations, but the direction of effect was evenly split among recommendations, even after accounting for variation in adherence to the interventions. The interesting pattern of regional differences in the recommendations affected suggests that contextual factors-other than those included in our model-could be operating at the local or network level.

Our findings raised practical and philosophical questions about the design of interventions to improve guideline implementation. Although practices were provided with validated tools and hands-on guidance, they were free to identify target goals, determine improvement strategies, and implement changes in any sequence. More significant gains might have been achieved had practices been encouraged to follow a prescribed, logical sequence of steps. For example, practices might have had greater success if we had urged that they first establish planned visits for all asthmatic patients, then specify content of visits, create templates and order sets in the record, and finally 
focus on creation of action plans. The importance of sequencing of improvement strategies should be further investigated to assist in guideline dissemination and implementation. ${ }^{7}$

\section{Limitations}

There are several limitations to this study. First, our study averaged 25 patients per practice, although we estimated that 60 were required for multivariable modeling with adjustment for clustering by practice. Many patients with a diagnosis of asthma in billing records did not have evidence of asthma in the medical record or had mild disease and were only seen occasionally. Despite a much smaller sample size than anticipated, we found a statistically significant improvement among the study arms assigned a practice facilitator compared with control practices for 2 outcomes. A larger sample may have yielded additional significant findings and enabled adjustment for clustering within practices.

All outcomes measured were intermediate, processoriented outcomes focused on practice behaviors but known to have positive impacts on patient outcomes. For example, reduced outpatient and emergency department visits, hospitalizations, and cost of asthma care have been clearly linked to higher rates of adherence to the NHLBI guidelines, particularly for use of controller medications and action plans. ${ }^{34,35}$

Inclusion of patient visits that occurred during the active intervention period may have blunted the size of the eventual measured effect of the interventions. It was also beyond the scope of our study to examine whether guideline improvements continued to improve or were sustained beyond 1 year postintervention.

It is possible that adherence to guideline recommendations could have increased simply because of the extra asthma-related visits in the PF group (more opportunities to adhere). Assessment of level of control, however, which was calculated as the percentage of visits at which this assessment was done, increased significantly in the PF group, suggesting that the interventions, rather than the number of visits, were driving the changes. We also cannot rule out the possibility that primary care clinicians were addressing asthma more often in this study arm as a result of the efforts of the practice facilitators, resulting in more asthmarelated visits.

It proved challenging to ensure that LLC meetings occurred monthly with all practices in attendance, and that practices could accommodate regular PF visits. Even so, the findings remained remarkably consistent after excluding those practices not adherent to the interventions.

Finally, although the study was not designed to collect data for cost-effectiveness analysis, our experience and that of others estimate the cost of a 6 -month practice facilitation intervention, including performance assessments, academic detailing, and supervision, to be between $\$ 7,500$ and $\$ 15,000$ per practice. ${ }^{21,36,37}$ The LLCs cost approximately one-half as much.

This study adds to the established literature showing the effectiveness of PF for at least some aspects of guideline implementation. Despite a smaller than expected sample size, we found that facilitation was significantly better than education, practical tools, and performance feedback alone in implementation of 2 of the 6 key NHLBI asthma guideline recommendations.

To read or post commentaries in response to this article, see it online at http:/lwww.annfammed.org/content/12/3/233.

Submitted July 23, 2013; submitted, revised, December 10, 2013; accepted December 20, 2013.

Key words: asthma; primary health care; practice-based research network; practice guidelines as topic; quality improvement; practice facilitation

Funding support: Financial support was received from the National Heart, Lung and Blood Institute, HHS-5R01HL091827.

Disclaimer: The views expressed here are those of the authors and do not necessarily reflect the views of the National Heart, Lung and Blood Institute.

Supplementary materials: Available at http://www.AnnFamMed. org/content/12/3/233/suppl/DC1/

\section{References}

1. Yawn BP, Yawn RA. Measuring asthma quality in primary care: can we develop better measures? Respir Med. 2006;100(1):26-33.

2. Cabana MD, Slish KK, Nan B, Lin X, Clark NM. Asking the correct questions to assess asthma symptoms. Clin Pediatr (Phila). 2005;44 (4):319-325.

3. Diette GB, Skinner EA, Markson LE, et al. Consistency of care with national guidelines for children with asthma in managed care. J Pediatr. 2001;138(1):59-64.

4. Diette GB, Patino CM, Merriman B, et al. Patient factors that physicians use to assign asthma treatment. Arch Intern Med. 2007;167 (13):1360-1366.

5. Apter AJ, Van Hoof TJ, Sherwin TE, Casey BA, Petrillo MK, Meehan TP. Assessing the quality of asthma care provided to Medicaid patients enrolled in managed care organizations in Connecticut. Ann Allergy Asthma Immunol. 2001;86(2):211-218.

6. Warman KL, Silver EJ, Stein RE. Asthma symptoms, morbidity, and antiinflammatory use in inner-city children. Pediatrics. 2001;108(2): 277-282.

7. Bender BG, Dickinson P, Rankin A, Wamboldt FS, Zittleman L, Westfall JM. The Colorado Asthma Toolkit Program: a practice coaching intervention from the High Plains Research Network. J Am Board Fam Med. 2011;24(3):240-248.

8. McMullen A, Yoos HL, Anson E, Kitzmann H, Halterman JS, Arcoleo KS. Asthma care of children in clinical practice: do parents report receiving appropriate education? Pediatr Nurs. 2007;33(1):37-44.

9. Beauchesne MF, Levert V, El Tawil M, Labrecque M, Blais L. Action plans in asthma. Can Respir J. 2006;13:306-10. 
10. Cloutier MM, Hall CB, Wakefield DB, Bailit H. Use of asthma guidelines by primary care providers to reduce hospitalizations and emergency department visits in poor, minority, urban children. J Pediatr. 2005;146(5):591-597.

11. DePue JD, Goldstein MG, Schilling A, et al. Dissemination of the AHCPR clinical practice guideline in community health centres. Tob Control. 2002;11(4):329-335.

12. Katz DA, Muehlenbruch DR, Brown RL, Fiore MC, Baker TB; AHRQ Smoking Cessation Guideline Study Group. Effectiveness of implementing the Agency for Healthcare Research and Quality smoking cessation clinical practice guideline: a randomized, controlled trial. J Natl Cancer Inst. 2004;96(8):594-603.

13. Freeborn DK, Shye D, Mullooly JP, Eraker S, Romeo J. Primary care physicians' use of lumbar spine imaging test. J Gen Intern Med. 1997;12(10):619-625.

14. Bland DR, Dugan E, Cohen SJ, et al. The effects of implementation of the Agency for Health Care Policy and Research urinary incontinence guidelines in primary care practices. J Am Geriatr Soc. 2003; 51(7):979-984.

15. Thompson C, Kinmonth AL, Stevens L, et al. Effects of a clinicalpractice guideline and practice-based education on detection and outcome of depression in primary care: Hampshire Depression Project randomised controlled trial. Lancet. 2000;355(9199):185-191.

16. Shojania KG, McDonald KMW. R. M., Owens DK. Closing the quality gap: a critical analysis of quality improvement srategies. In: AHRQ Publication No. 04(07)-0051-5; 2007.

17. Wilcock PM, Campion-Smith C, Head M. The Dorset Seedcorn Project: interprofessional learning and continuous quality improvement in primary care. Br J Gen Pract. 2002;52(Suppl):S39-S44.

18. Bertoni $A G$, Bonds $D E$, Chen $H$, et al. Impact of a multifaceted intervention on cholesterol management in primary care practices. Arch Intern Med. 2009;169(7):678-686.

19. Ornstein S, Nietert PJ, Jenkins RG, Wessell AM, Nemeth LS, Rose $\mathrm{HL}$. Improving the translation of research into primary care practice: results of a national quality improvement demonstration project. Jt Comm J Qual Patient Saf. 2008;34(7):379-390.

20. Baskerville NB, Liddy C, Hogg W. Systematic review and metaanalysis of practice facilitation within primary care settings. Ann Fam Med. 2012;10(1):63-74.

21. Knox L, Taylor EF, Geonnotti K, et al. Developing and running a primary care practice facilitation program: a how-to guide. AHRQ Publication No. 12-0011, December 2011.

22. Nagykaldi Z, Mold JW, Aspy CB. Practice facilitators: a review of the literature. Fam Med. 2005;37(8):581-588.
23. Mittman BS. Creating the evidence base for quality improvement collaboratives. Ann Intern Med. 2004;140(11):897-901.

24. ØVretveit J, Bate P, Cleary P, et al. Quality collaboratives: lessons from research. Qual Saf Health Care. 2002; 11(4):345-351.

25. Cretin S, Shortell SM, Keeler EB. An evaluation of collaborative interventions to improve chronic illness care. Framework and study design. Eval Rev. 2004;28(1):28-51.

26. Young PC, Glade GB, Stoddard GJ, Norlin C. Evaluation of a learning collaborative to improve the delivery of preventive services by pediatric practices. Pediatrics. 2006;117(5):1469-1476.

27. Pearson ML, Wu S, Schaefer J, et al. Assessing the implementation of the chronic care model in quality improvement collaboratives. Health Serv Res. 2005;40(4):978-996.

28. Rogers EM. Change agents. In: Rogers, ed. Diffusion of Innovations. 5th ed. New York, NY: Free Press; 2003.

29. Lineker SC, Bell MJ, boyle J, et al. Implementing arthritis clinical practice guidelines in primary care. Med Teacher. 2009;31:230-7.

30. Mangione-Smith R, Schonlau M, Chan KS, et al. Measuring the effectiveness of a collaborative for quality improvement in pediatric asthma care: does implementing the chronic care model improve processes and outcomes of care? Ambul Pediatr. 2005;5(2):75-82.

31. Aspy CB, Mold JW, Thompson DM, et al. Integrating screening and interventions for unhealthy behaviors into primary care practices. Am J Prev Med. 2008;35(5)(Suppl):S373-S380.

32. NHLBI. National Ashma Education and Prevention Program. Guidelines for the Diagnosis and Management of Asthma. Washington, DC: NIH; 2007. Report No.: Expert Panel Report 3.

33. Yawn BP, Bertram S, Wollan P. Introduction of Asthma APGAR tools improve asthma management in primary care practices. J Asthma Allergy. 2008;1:1-10.

34. Cloutier MM, Grosse SD, Wakefield DB, Nurmagambetov TA, Brown $\mathrm{CM}$. The economic impact of an urban asthma management program. Am J Manag Care. 2009;15(6):345-351.

35. Bateman ED, Frith LF, Braunstein GL. Achieving guideline-based asthma control: does the patient benefit? Eur Respir J. 2002;20(3): 588-595.

36. Hogg W, Baskerville N, Lemelin J. Cost savings associated with improving appropriate and reducing inappropriate preventive care: cost-consequences analysis. BMC Health Serv Res. 2005;5(1):20.

37. Culler SD, Parchman ML, Lozano-Romero R, et al. Cost estimates for operating a primary care practice facilitation program. Ann Fam Med. 2013;11(3):207-211. 